\title{
Effects of Propolis and Black Seed Oil on the Shelf Life of
}

\section{Freshly Squeezed Pomegranate Juice}

\author{
Ibrahim Kahramanoglu ${ }^{1,2^{*}} \&$ Serhat Usanmaz ${ }^{1}$ \\ ${ }^{1}$ Department of Horticultural Production and Marketing, European University of Lefke, Lefke, Cyprus \\ ${ }^{2}$ Alnar Narc1lık Ltd., Güzelyurt, Cyprus \\ * Ibrahim Kahramanoglu, E-mail: ibrahimcy84@yahoo.com
}

Received: October 23, 2017 Accepted: October 30, 2017 Online Published: November 6, 2017

doi:10.22158/fsns.v1n2p114 URL: http://dx.doi.org/10.22158/fsns.v1n2p114

\begin{abstract}
During the last decade, consumers began to pay more attention on the 100\% natural, pure and Not From Concentrate (NFC) fruit juice. However, 100\% natural fruit juice has shorter shelf life than the concentrated juice, due to the development of yeast and mould. Therefore, present research aimed to study the effects of propolis and black seed oil on the shelf life of freshly squeezed pomegranate juice. According to the results obtained, both propolis and black seed oil have delaying effect on the development of yeast and mould. Moreover, it was also found that combination of these treatments with freezing, increases the efficiency of tested natural treatments, as well as the shelf life.
\end{abstract}

\section{Keywords}

fresh juice, shelf life, colony forming unit, ascorbic acid, maturity index

\section{Introduction}

Pomegranate (Punica granatum L.) is predicted to be among the oldest known cultivated fruit crops. Result of some scientific studies showed that antioxidant and anti-microbial capacity of pomegranate fruit are high, it decreases blood pressure and it can be used against some illness such as cancer and diabetic (Aviram et al., 2000; Jurenka, 2008). However, consumption of pomegranate fruit is difficult due to the hassle of aril extraction. On the other hand, pomegranate has lots of low quality products as a result of sunburn and fruit cracking. Therefore, using low quality products for juice production is important for both producers and consumers. The demand for $100 \%$ natural, pure and Not From Concentrate (NFC) juice is increasing because of the increase in consumer awareness on the negative effects of synthetic food additives on human health (AIJN, 2016). However, development of yeast and mould cause $100 \%$ natural pomegranate juice to have shorter shelf life as in many other fruit juice. Although, the shelf life of pomegranate juice can be prolonged by using chemical additives i.e. sodium benzoate and potassium sorbate, changes in the consumer preferences has been directed producers to 
find alternative natural and healthy methods. In the light of this information, present work aimed to study the effects of propolis and black seed oil on the shelf life of freshly squeezed pomegranate juice.

\section{Meterials and Methods}

Pomegranate fruit samples of present study are belonging to the Wonderful culturae, which has been dominating pomegranate trade in the world. This culturae was originated in Florida. Fruit size of this culturae is big with deep-red fruit color. Fruit juice content is high and taste is sweet-tart. Harvesting period is between October and November in the northern hemisphere. Fruit samples of present study were harvested on October 2015, from a 7-years old pomegranate orchard located in Güzelyurt province in Cyprus. Fruits were harvested by hand at commercial maturity ( $>17 \%$ TSS and $>1.80$ titratable acidity) and immediately after harvest, fruits were transferred to the factory of Alnar Narcilik Ltd. with a ventilated truck. After that, arils were extracted from the fruits by automatic machine and arils were pressed to produce juice.

Crude propolis was gathered by hand from Bağliköy province in the western part of Cyprus. The propolis exudates collected by bees (Apis mellifera cypria) were primarily from a mixture of wild and cultivated plant species, including pine (Pinus brutia L.), olive (Olea europea L.), eucalyptus (Eucalyptus globulus L.), citrus (Citrus spp.), trifoliums (Medicago spp. and Trifolium spp.), pimpernel (Anagallis arvensis L.), hordeum (Hordeum bulbosum L.), field bindweed (Convolvulus arvensis L.), chrysanths (Chrysanthemum spp.) and locust (Acacia spp.). Preparation of the propolis extract was done according to the method by Krell (1996) with some modifications. The propolis extracts were frozen to $-20^{\circ} \mathrm{C}$ for 1 month, then cut in small pieces, and ground in a chilled mortar. After that, $10 \%$ ethanol extracted propolis was prepared by adding $100 \mathrm{~g}$ of the propolis to $900 \mathrm{~mL}$ of $70 \%$ ethanol and agitating for 1 week. Agitating was done with automatic machine by shaking the extract for 1 minute with 60 minutes interval. The mixture was maintained at room temperature during preparation and was subsequently filtered through Whatman 1 filter paper. The extracts were kept at $4^{\circ} \mathrm{C}$ in dark storage until use.

Black seed oil is a product of Nigella Sativa plant which is native to Asia. The black seed oil of present study is belonging to the Pelmur Ltd. with a brand name of Biotama. The black seed oil is obtained by the cold-press of black cumin seeds. The purchased black seed oil was $100 \%$ pure and was dissolved in ethanol by adding $100 \mathrm{~mL}$ of the black seed oil to $900 \mathrm{~mL}$ of $70 \%$ ethanol and agitating for 1 day.

First of all, pomegranate juice was pasteurized for 15 second at $72^{\circ} \mathrm{C}$ and it cooled to $4^{\circ} \mathrm{C}$ in 4 minutes. Immediately after that, pomegranate juice was filled in $250 \mathrm{ml}$ bottles. Numbers of main treatments of present study are 3, which are: (1) untreated control, (2) propolis application [1 drop/250 ml] and (3) black seed oil application [1 drop/250 ml]. All treatments were subjected to 2 different factors, these are: (a) shelf life test after filling [storage at $4^{\circ} \mathrm{C}$ ] (b) shelf life test after 1 year storage at $-18^{\circ} \mathrm{C}$ [storage at $4^{\circ} \mathrm{C}$. Experiments were set up with 145 samples for each unique treatment. Five samples from each unique treatment were subjected to yeast and mould analyzes (colony forming unit-cfu/g) for 2-days 
intervals starting from the $5^{\text {th }}$ day (totally 29 measurements). Therefore, experiments were continued for 61 days in total. Moreover, following tests were conducted for the samples of (i) 0 day after squeezing, (ii) 15 days after squeezing, and (iii) 380 days after squeezing [15 days shelf life after 1 year freezing storage]. The tests were: (1) antioxidant activity (\%), (2) Total Soluble Solids (TSS), (3) titratable acidity (\%), and (4) ascorbic acid content [mg/L].

Determination of yeasts and moulds was done as colony forming unit/g. For this $1 \mathrm{~mL}$ of each juice was placed on plate surface that contained Sabouraud Dextrose Agar (SDA) and distributed by a sterilized swab. Plates were incubated for 5 days at $25^{\circ} \mathrm{C}$. Colonies were counted and expressed as cfu/g. The antioxidant activity of the pomegranate juice was evaluated using the DPPH free radical-scavenging method. Measurements were carried out according to the modified method of Klimczak et al. (2007). A total of $5 \mathrm{~mL}$ pomegranate juice was mixed with $5 \mathrm{~mL}$ of methyl alcohol $(80 \%)$ in teflon tubes and then centrifuged $\left(4000 \mathrm{rpm}, 10 \mathrm{~min}\right.$, at $\left.4^{\circ} \mathrm{C}\right)$. Briefly, $0.1 \mathrm{~mL}$ of supernatant was added to $2.46 \mathrm{~mL}$ of 1,1-diphenyl-2-picrylhydrazyl radical (DPPH; $0.1 \mathrm{mg} / \mathrm{L}$ in $80 \%$ methyl alcohol) and mixed by vortex. Absorbance of the samples was measured at $515 \mathrm{~nm}$ using the spectrophotometer after incubating for $10 \mathrm{~min}$ in the dark. Antioxidant activity was expressed as the percentage decline of the absorbance from control group.

Total soluble solids content of the fruits were measured by a hand refractometer. Titratable acidity ( $\mathrm{g} / 100 \mathrm{~g}$ of citric acid) of juice samples was determined according to AOAC (1990) with WTW $\mathrm{pH}$-meter (Weilheim, Germany). Titratable acidity was determined by titrating $2 \mathrm{~mL}$ of fruit juice in 38 $\mathrm{mL}$ of distilled water with $0.1 \mathrm{~N} \mathrm{NaOH}$ to an end point of $\mathrm{pH}$ 8.1. Ascorbic acid determination was performed by following the method of Lee and Coates (1999) by using the HPLC method. The HPLC column was maintained at $25^{\circ} \mathrm{C}$ and the flow rate was $0.5 \mathrm{~mL} \mathrm{~min}^{-1}$. A total of $10 \mu \mathrm{L}$ supernatant was injected into the C18 XTerra (Waters, $4.6 \times 250 \mathrm{~mm}$ ) column. The photodiode array detector was set at $244 \mathrm{~nm}$, and $2 \% \mathrm{KH}_{2} \mathrm{PO}_{4}(\mathrm{pH} 2.4)$ was used as the mobile phase.

Collected data was summarized by using Microsoft Excel and figures and simple tables were prepared with the mean and standard deviations. The data of the experiments was subjected to analysis of variance (ANOVA) with main treatments and storage conditions as factors using SPSS software. Mean separations was done by using Tukeys (HSD) multiple range test at $\mathrm{P} \leq 0.05$. Significant differences were showed at the tables by using different letters.

\section{Results and Discussions}

Results for the development of yeast and mould at the juice samples which were subjected to different treatments are given in Figure 1. It is clear from the figure that yeast and mould development was firstly observed at the control treatment at $15^{\text {th }}$ day. Colony forming unit was $72 \pm 41$ at $15^{\text {th }}$ day and it increased with the increase in the storage duration. According to the result it can be concluded that freshly squeezed pomegranate juice can be stored for $15^{\text {th }}$ days at $4^{\circ} \mathrm{C}$ without any additive (with pasteurization at $72^{\circ} \mathrm{C}$ for $15 \mathrm{sn}$ ). Development of yeast and mould had been observed at $19^{\text {th }}$ day of 
control treatment when samples stored 1 year at $-18^{\circ} \mathrm{C}$ and then taken out to shelf. These result shows that freezing of freshly squeezed pomegranate juice delays the development of yeast and mould for 4 days. Frozen storage is known to have less detrimental effect on the juice.

Application of both propolis and black seed oil had been found to delay the development of yeast and mould. First measurement of colony forming unit for the application black seed oil and propolis were at $21^{\text {th }}$ and $23^{\text {th }}$ days, respectively. Similarly Koç et al. (2007) conducted a study about the anti-fungal effects of propolis in 4 different fruit juice (mandarin, orange, apple and white grape). They reported that presence of propolis inhibited the growth of all spoilage yeast at $25^{\circ} \mathrm{C}$. However, that study was conducted for only 48 hours. Anti-fungal activity of propolis was also reported by some other scientist (Özcan, 1999; Oliveira et al., 2006; Senka et al., 2011; Temiz et al., 2013). On the other hand, Hafez (2008) reported that $0.5 \%$ black seed oil application on the cucumber had showed protective effect against powdery mildew. In another study, Forouzanfar et al. (2014) reported that black seed oil contains thymoquinone which has high anti-microbial activity. They also noted that black seed oil had a strong antibacterial activity against all the strains of L. monocytogenes. In present study, similar with the control treatment, freezing had been found to delay the development of yeast and mould for both the application of propolis and black seed oil. Yeast and mould development had firstly observed at $33^{\text {th }}$ day for black seed oil application. This means that freezing helped the black seed oil to increase the shelf life of pomegranate juice for 12 more days. The best result (longer shelf life) had been obtained from propolis application + freezing, where the development yeast and mould was suppressed until $37^{\text {th }}$ day.

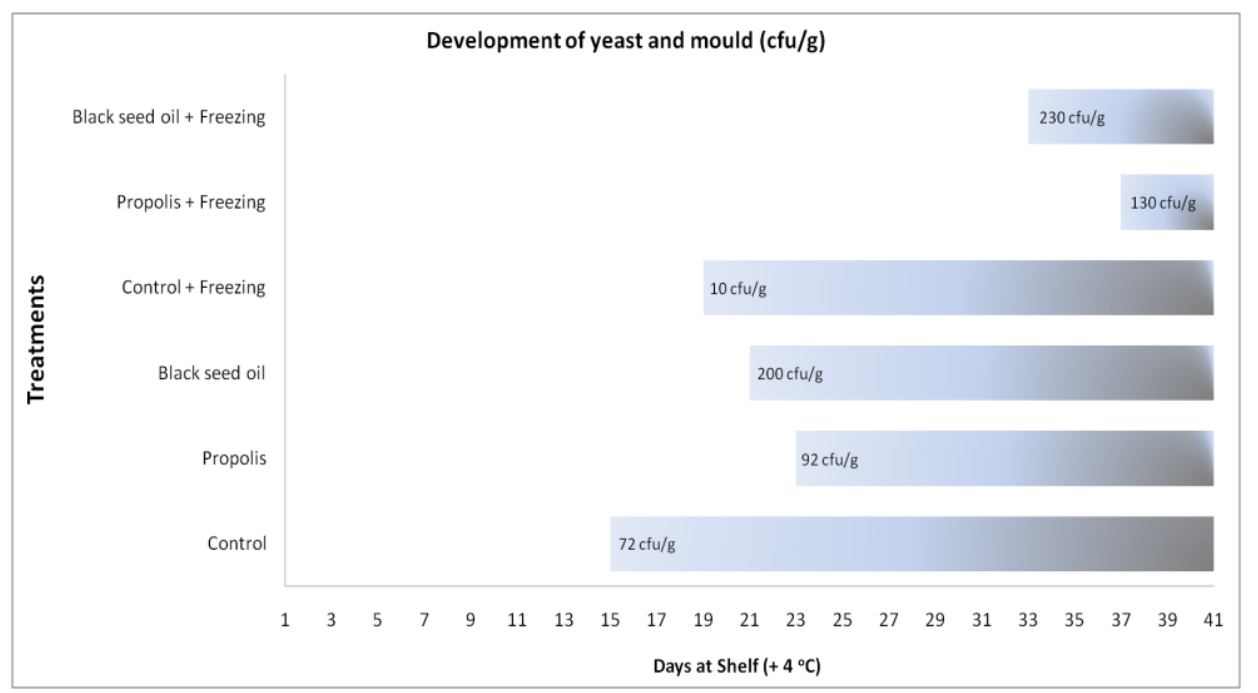

Figure 1. Effects of Propolis and Black Seed Oil on the Yeast and Mould Development

Antioxidants protect the body from the harmful effects of free radicals. Antioxidants include some vitamins (i.e., vitamins $\mathrm{C}$ and $\mathrm{E}$ ), some minerals and flavonoids, which are found in plants. Pomegranate fruit is among the good sources of antioxidants (Valko et al., 2007). Antioxidant activity 
of samples measured as $95.6 \pm 0.17$ immediately after squeezing. At $15^{\text {th }}$ day it was observed that antioxidant activity of all treatments decreased (Table 1). According to the results, antioxidant activity of control treatment was found to be significantly lower than the other treatments. When the samples stored 1 year at $-18^{\circ} \mathrm{C}$, it was determined that antioxidant activity continued to decrease. However, at the same time antioxidant activity of control treatment was again found to be lower than the other treatments.

Table 1. Effects of Propolis and Black Seed Oil on the Antioxidant Activity

\begin{tabular}{llll}
\hline \multirow{2}{*}{ Treatments } & \multicolumn{2}{l}{ Antioxidant activity $(\%)$} & \\
\cline { 2 - 4 } & Day 0 & Day 15 & Day 15 after 1 year freezing \\
\hline Control & $95.6 \pm 0.17 \mathrm{a}$ & $93.3 \pm 0.12 \mathrm{~b}$ & $90.5 \pm 0.22 \mathrm{~b}$ \\
Propolis & $95.6 \pm 0.17 \mathrm{a}$ & $94.4 \pm 0.15 \mathrm{a}$ & $92.8 \pm 0.11 \mathrm{a}$ \\
Black seed oil & $95.6 \pm 0.17 \mathrm{a}$ & $94.2 \pm 0.04 \mathrm{a}$ & $92.5 \pm 0.14 \mathrm{a}$ \\
\hline
\end{tabular}

Values followed by the same letter or letters within same column are not significantly different at a $5 \%$ level (Tukeys (HSD) multiple range test).

Ascorbic acid is among the important components of pomegranate (Miguel et al., 2010). However, it is believed that the storage duration of fruit causes a decline in the concentration of ascorbic acid (Zarei et al., 2011; Kulkarni \& Aradya, 2005). As stated by these studies, the ascorbic acid content of pomegranate juice showed a considerable decline during storage in present study (Table 2). The ascorbic acid in control treatment decreased from $70.3 \mathrm{mg} / \mathrm{L}$ to $66.7 \mathrm{mg} / \mathrm{L}$ in 15 days of storage at shelf. The ascorbic acid content of other treatments also showed a decline but for both propolis and black seed oil applications, it was found to be higher than the control treatment. When the samples freeze for 1 year, the ascorbic acid content for control, propolis and black seed oil treatments were found to decrease until 18.7, 23.9, 23.3, respectively.

Table 2. Effects of Propolis and Black Seed Oil on the Ascorbic Acid

\begin{tabular}{llll}
\hline \multirow{2}{*}{ Treatments } & \multicolumn{2}{l}{ Ascorbic acid (mg/L) } \\
\cline { 2 - 4 } & Day 0 & Day 15 & Day 15 after 1 year freezing \\
\hline Control & $70.3 \pm 0.45 \mathrm{a}$ & $66.7 \pm 0.23 \mathrm{c}$ & $18.7 \pm 0.38 \mathrm{~b}$ \\
Propolis & $70.3 \pm 0.45 \mathrm{a}$ & $67.8 \pm 0.88 \mathrm{a}$ & $23.9 \pm 0.49 \mathrm{a}$ \\
Black seed oil & $70.3 \pm 0.45 \mathrm{a}$ & $67.3 \pm 0.11 \mathrm{ab}$ & $23.3 \pm 0.17 \mathrm{a}$ \\
\hline
\end{tabular}

Values followed by the same letter or letters within same column are not significantly different at a 5\% level (Tukeys (HSD) multiple range test). 
The ratio (maturity index) between Total Soluble Solids content (TSS) and Titratable Acidity (TA) is the main factor determining pomegranate fruit taste and fruit maturity (Cristosto et al., 2000). The Maturity Index (MI) is related to the taste and flavor of fruit. The MI of present study is determined as 9.7 at the first day of juice production (Table 3 ).

Table 3. Effects of Propolis and Black Seed Oil on the Maturity Index

\begin{tabular}{llll}
\hline \multirow{2}{*}{ Treatments } & \multicolumn{4}{l}{ Maturity index (TSS/TA) } \\
\cline { 2 - 4 } & Day 0 & Day 15 & Day 15 after 1 year freezing \\
\hline Control & $9.7 \pm 0.24 \mathrm{a}$ & $10.3 \pm 0.19 \mathrm{a}$ & $23.2 \pm 0.6 \mathrm{a}$ \\
Propolis & $9.7 \pm 0.24 \mathrm{a}$ & $10.2 \pm 0.12 \mathrm{a}$ & $18.9 \pm 0.5 \mathrm{c}$ \\
Black seed oil & $9.7 \pm 0.24 \mathrm{a}$ & $10.3 \pm 0.10 \mathrm{a}$ & $21.8 \pm 0.2 \mathrm{~b}$ \\
\hline
\end{tabular}

Values followed by the same letter or letters within same column are not significantly different at a $5 \%$ level (Tukeys (HSD) multiple range test).

The maturity index showed slight increase in 15 days of storage at shelf. At that time, no significant difference was determined among the treatments. Approximately 2 -fold increase had been determined at the samples when they freeze for 1 year and then taken out to the shelf for $15^{\text {th }}$ days. Main reason of increase in the maturity index is the considerable decrease in the titratable acidity. At $15^{\text {th }}$ day, significant differences were calculated for the different treatments. The lowest maturity index was determined from the propolis treatment and highest from control. When the maturity index of a food increases, it causes the food to be sweeter. Not only for the pomegranate juice, but for all juice types, consumers do not prefer high changes in the taste. Therefore, it can be concluded that application of propolis reduces this change in the taste. Application of black seed oil has also been found to have significant effect on the maturity index, but lower than the propolis application.

\section{Conclusions}

Yeast and the mould are the main reason for the spoilage of freshly squeezed pomegranate juice and thus main cause of the decrease in the shelf life. In present study, propolis and black seed oil applications showed good performance in controlling the development of yeast and mould. The efficiency of both treatments showed considerable increase; when they combined with freezing technique. Results suggested that the shelf life of freshly squeezed pomegranate juice can be extended to 37 days with the application of propolis ( $1 \mathrm{drop} / 250 \mathrm{ml}$ ) plus freezing. On the other hand, both propolis and black seed oil applications have been found to protect anti-oxidant activity, ascorbic acid content and maturity index, as compared to control treatment. 


\section{References}

AIJN. (2016). Liquit Fruit 2016 Market Report, Eruropean Fruit Juice Association, Brussels (p. 43). Retrieved from http://www.aijn.org

AOAC. (1990). Official Method of Analysis of the Association of Official Analytical Chemistry (15th ed.). AOAC, Arlington, Va, USA.

Aviram, M., Dornfeld, L., Rosenblat, M., Volkova, N., Kaplan, M., Coleman, R., ... Fuhrman, B. (2000). Pomegranate juice consumption reduces oxidative stress, atherogenic modifications to LDL, and platelet aggregation: Studies in humans and in atherosclerotic apolipoprotein E-deficient mice. The American Journal of Clinical Nutrition, 71, 1062-1076 [Abstract only].

Cristosto, C. H., Mitcham, E. J., \& Kader, A. A. (2000). Pomegranate: Recommendations for maintaining postharvest quality. Produce Facts Postharvest Research and Information Centre, University of California, Davis, USA. Retrieved August 3, 2017, from http://www.postharvest.ucdavis.edu/PFfruits/Pomegranate/

Forouzanfar, F., Bazzaz, B. S. F., \& Hosseinzadeh, H. (2014). Black cumin Nigella sativa and its constituent (thymoquinone): A review on antimicrobial effects. Iranian Journal of Basic medical Science, 17, 929-938.

Hafez, Y. M. (2008). Effectieness of the antifungal black seed oil against powdery mildews of cucumber (Podosphaera xanthii) and barley (Blumeari graminis f.sp. hordei). Acta Biologica Szegediensis, 52(1), 17-25.

Jurenka, J. (2008). Therapeutic applications of Pomegranate: A review. Alternative Medicine Review, 13(2), 128-144.

Klimczak, I., Malecka, M., Szlachta, M., \& Gliszczyńska-Świglo, A. (2007). Effect of storage on the content of polyphenols, vitamin $\mathrm{C}$ and the antioxidant activity of orange juices. J. Food Compos Anal, 20, 313-322. https://doi.org/10.1016/j.jfca.2006.02.012

Koc, A. N., Silici, S., Mutlu-Sariguzel, F., \& Sagdic, O. (2007). Antifungal activity of Propolis in four different fruit juices. Food Technol. Biotechnol., 45(1), 57-61.

Krell, R. (1996). Value-Added Products from Beekeeping. FAO Agricultural Services Bulletin (No. 124, pp. 85-89). Food and Agriculture Organization of the United Nation, Rome.

Kulkarni, A. P., \& Aradhya, S. M. (2005). Chemical changes and antioxidant activity in pomegranate arils during fruit development. Food Chemistry, 93, 319-324. https://doi.org/10.1016/j.foodchem.2004.09.029

Lee, H. S., \& ve Coates, G. A. (1999). Vitamin C in frozen, fresh squeezed, unpasteurized, polyethylene-bottled orange juice: A storage study. Food Chemistry, 65(2), 165-168. https://doi.org/10.1016/S0308-8146(98)00180-0

Miguel, M. G., Nevesa, M. A., \& Antunes, M. D. (2010). Pomegranate (Punica granatum L.): A medicinal plant with myriad biological properties. Journal of Medicinal Plants Research, 4, 2836-2847. 
Oliveira, A. C. P., Shinobu, C. S., Longhini, R., Franco, S. L., \& Svidzinski, T. I. E. (2006). Antifungal activity of propolis extract agaist yeasts isolated from onychomycosis lesions. Mem Inst Oswaldo Cruz, 101(5), 493-497. https://doi.org/10.1590/S0074-02762006000500002

Özcan, M. (1999). Antifungal properties of propolis. Grass y aeites, 50(5), 395-398. https://doi.org/10.3989/gya.1999.v50.i5.685

Senka, B., Pasic, S., Behija, D., \& Agnesa, C. (2011). Antifungal activity of propolis originated from Bosnia and Herzegovina. Veterinaria, 60(3-4), 187-193.

Temiz, A., Mumcu, A. Ş., Tüylü, A. Ö., Sorkun, K., \& Salih, B. (2013). Antifungal activity of Propolis samples collected from different geographical regions of Turkey against two food-related molds, Aspergillus versicolor and Penicillium aurantiogriseum. GIDA, 38(3), 135-142.

Valko, M., Leibfritz, D., Moncol, J., Croninc, M. T. D., Mazura, M., \& Telserd, J. (2007). Free radicals and antioxidants in normal physiological functions and human disease. International Journal of Biochemistry and Cell Biology, 39(1), 44-84. https://doi.org/10.1016/j.biocel.2006.07.001

Zarei, M., Azizi, M., \& Bashir-Sadr, Z. (2011). Evaluation of physicochemical characteristics of pomegranate (Punica granatum L.) fruit during ripening. Fruits, 66, 121-129. https://doi.org/10.1051/fruits/2011021 